\title{
Retraction Note: Oleandrin-Mediated Expression of Fas Potentiates Apoptosis in Tumor Cells
}

Yashin Sreenivasan • Pongali B. Raghavendra •

Sunil K. Manna

Published online: 4 April 2013

(C) Springer Science+Business Media New York 2013

Retraction to: J Clin Immunol (2006) 26:308-322

DOI 10.1007/s10875-006-9028-0

This article has been retracted at the request of the Centre for DNA Fingerprinting and Diagnostics as it contains manipulated figures. 